\title{
Never Let a Good Crisis Go to Waste: Agenda Setting and Legislative Voting in Response to the EU Crisis
}

\author{
Jack Blumenau, University College London \\ Benjamin E. Lauderdale, London School of Economics
}

The European Union's policy response to the recent global economic crisis transferred significant powers from the national to the European level. When exogenous shocks make status quo policies less attractive, legislators become more tolerant to proposed alternatives, and the policy discretion of legislative agenda setters increases. Given control of the EU agenda-setting process by pro-integration actors, we argue that this dynamic explains changes in voting patterns of the European Parliament during the crisis period. We observe voting coalitions increasingly dividing legislators along the pro-anti integration, rather than the left-right dimension of disagreement, but only in policy areas related to the crisis. In line with more qualitative assessments of the content of passed legislation, the implication is that prointegration actors were able to shift policy further toward integration than they could have without the crisis.

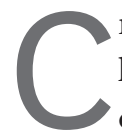
rises are commonly assumed to be catalysts for political action, opening "windows of opportunity" for dramatic and far-reaching reform (Cortell and Peterson 1999; Keeler 1993; Kingdon 1995). Similarly, crises can represent "critical junctures" that are central to explanations of the punctuated dynamic of institutional change (Baumgartner et al. 2009; Baumgartner and Jones 2002; Collier and Collier 2002; Krasner 1984; Peters et al. 2005; Pierson 2000; Thelen 2004). One way that crises can facilitate political action is by weakening impediments that constrain agendasetting actors. When this happens, those agenda setters are able to "make an opportunity out of a crisis" and secure changes that would have been impossible previously. However, beyond broad arguments that impediments to political action are removed, we often lack detailed theory of the effects that crises have on specific political decision-making processes. Further, which actors benefit from crises? Although "policy entrepreneurs" are well positioned to benefit from crises (Kingdon 1995), it is important to specify why crises represent "an opportunity to be exploited" (Keeler 1993, 441) for some actors but not for others. We address these questions by describing a model of the relationship between crises, legislative voting behavior, and agenda setting, which we apply to understanding the European Union's response to the 2008 global financial crisis.

The model we describe implies that crises weaken a key impediment to policy change: the opposition of legislators. This provides microfoundations for the broader "crisis as opportunity" thesis. Legislatures are a key part of the decision-making apparatus of all democracies and act as a major constraint on policy change under "normal" political conditions. There exist few accounts of legislative behavior in times of crisis. In contrast, there is extensive work on the impact of exogenous shocks on other political phenomena such as government duration and termination (Browne, Frendreis, and Gleiber 1986; Lupia and Strøm 1995), ministerial turnover (Diermeier and Merlo 2000; Martinez-Gallardo 2011), policy change (Luong and Weinthal 2004; Williams 2009), judicial decisions (Clark 2006; Epstein et al. 2005), and public opinion (Aldrich et al. 2006; Ladd 2007). Of the legislative studies that do evaluate the effects of such external shocks, there has been disproportionate focus on the effects of war on voting behavior in the US Congress (Cohen 1982; Howell and Rogowski 2013; Meernik 1993; Prins and Marshall 2001). This literature provides evidence of the "rally round the flag" effect but is largely silent on the mechanisms that link crises to individual decisions made

Jack Blumenau (j.blumenau@lse.ac.uk) is a lecturer in the Department of Political Science, University College London. Benjamin Lauderdale (b.e.lauderdale@lse.ac.uk) is an associate professor in the Department of Methodology, London School of Economics.

Data and supporting materials necessary to reproduce the numerical results in the paper are available in the JOP Dataverse (https://dataverse.harvard.edu /dataverse/jop). An online appendix with supplementary material is available at http://dx.doi.org/10.1086/694543.

The Journal of Politics, volume 80, number 2. Published online January 22, 2018. http://dx.doi.org/10.1086/694543

(C) 2018 by the Southern Political Science Association. All rights reserved. 0022-3816/2018/8002-0007\$10.00 
by legislators. Howell and Rogowski $(2013,164)$ encourage scholars to "pay closer attention to the microfoundations of legislative decision making" in times of war, advice that clearly applies more generally to crisis response. Additionally, while existing accounts highlight the potentially destabilizing effects of crises on policy, they do not generally provide specific predictions for the direction that policy will shift in response to a crisis. For example, the institutionalist literature is unclear as to what form new institutions will take following an equilibria punctuating shock. As Blyth $(2002,8)$ argues, "structural theories of institutional supply are indeterminate as to subsequent institutional form."

Our argument applies the core insight of the agenda setting model originally developed by Romer and Rosenthal (1978) to the context of a legislature facing a crisis in the face of preexisting multidimensional disagreements. By making the outcomes resulting from inaction less attractive, crises strengthen the position of agenda-setting actors in the policy process. Crises can be understood as shocks to the external conditions that frame legislative deliberations. In our model, legislators have preferences over the ideological content of the bills that they pass, but have a common interest in the extent to which policy is well suited to current conditions - which we will call the "valence" of policy. By changing the external context, a crisis reveals deficiencies in existing policies, makes status quo policies worse for all legislators, and thus encourages them to accept replacements. Accordingly, agenda-setting actors have more discretion during a crisis-period, and are able to propose (and pass) policy that would have been impossible in the absence of a crisis. When standing political disagreements are multidimensional, we show that such a model implies changes in legislative voting coalitions. Such shifts not only provide evidence that policy is moving toward the agenda setter's position but can also constitute a realignment of the primary dimension of political disagreement.

This model is well suited to understanding the effects of the global financial crisis on the voting behavior in the European Parliament (EP), where politics has traditionally operated in two dimensions: left-right and pro-anti integration (Hix 2002; Hix, Noury, and Roland 2006, 2007; Høyland 2010; Kreppel 2000; Kreppel and Tsebelis 1999). We argue that, in the context of the crisis, members of the European Parliament (MEPs) became more tolerant toward policies that they might previously have opposed; pro-integration agenda setters (the European Commission, the Council of the European Union, and the leaders of the large European Parliamentary Groups [EPGs]) exploited this tolerance to pass highly integrationist policy. Following the logic of our theoretical argument, this should have led to a shift in the voting patterns of the legislature, with voting coalitions increasingly dividing legislators into pro versus anti integration coalitions rather than left versus right coalitions.

We provide evidence that this occurred by combining topic modeling with a two-stage least-squares procedure in order to construct synthetic control comparisons to legislation in the precrisis period. We show that there was a shift toward voting along the pro-anti integration dimension during the crisis period but only on crisis-related issues. The crisis did not occasion the sort of shift toward integrationist policy that might have resulted if the crisis simply made MEPs more favorable toward integration in general: changes were confined to the crisis-related policy areas where status quo policies were increasingly viewed as untenable.

The EU policy response to the crisis was dramatic and far-reaching, and while some attention has been paid to the crisis response of the Commission (Copeland and James 2014) and the national governments in the European Council (Schimmelfennig 2014; Tsebelis and Hahm 2014), the only research of which we are aware that investigates how the crisis affected MEP votes focuses on the cohesion of EPGs and is based on a limited number of roll-call votes (Braghiroli 2015). While we are not the first to observe that the Commission and the Council were strengthened vis-à-vis other actors during the crisis, our argument attributes this change to how the crisis weakened the Parliament's ability to block policy changes. That the Commission and the Council appeared to be the central actors in the EU policy response is not the entire story: it was the crisis itself that undermined the Parliament's ability to stand in the way.

\section{POLITICS OF CRISIS IN THE EU Background}

In order to evaluate the effects of the crisis on the behavior of MEPs and on the agenda of the European Parliament, we first discuss two stylized facts supported by past research on EP politics that constitute key assumptions of our analysis. The first stylized fact is that policy preferences in the European Parliament can be described in terms of two major dimensions. One dimension corresponds to the left-right issues that typically shape national-level politics, while the second dimension relates to the scope of authority of European institutions, with those favouring more European powers at one end and those opposing the expansion of these powers at the other. This structure manifests itself clearly in roll-call (Hix et al. 2006, 2007; Hix and Noury 2009; Høyland 2010; Klüver and Spoon 2015) and expert survey (McElroy and Benoit 2007, 2011) data. The distribution of European Party Group (EPG) positions over these two dimensions are an inverted-U shape, where centrist parties (on the left-right dimension) tend to have relatively strong pro-integration 
preferences, whereas parties toward the extremes of the leftright space tend to be more anti-integrationist.

The second stylized fact is that although agenda control in the European Union is diffuse (Hix and Hoyland 2011), the main agenda-setting actors - the European Commission, the Parliament's Conference of Presidents, and the European Council - are united by their pro-integration preferences. The European Commission - a supranational body appointed by the governments of EU member states-holds the exclusive right to legislative initiative within the European Union. The Commission is the ultimate external gatekeeper in the EUwide policy process (Hix et al. 2007, 111), and recent literature has emphasized the key role of the Commission as agenda setter during the crisis period (Copeland and James 2014). The Commission is usually assumed to be pro-integration (Hooghe 2005; Mattila 2004; Tsebelis and Kreppel 1998) and has generally proved to be so in matters relating to the economic crisis.

The internal agenda of the parliament is largely controlled by the leaders of the EPGs through the Conference of Presidents, a political body responsible for the organization of parliamentary business (Kreppel 2002, 210). Through the Conference, party group leaders determine the agenda for plenary sessions, and a voting system that is weighted by party size allows the larger party groups - such as the EPP, ALDE, and the $\mathrm{S} \& \mathrm{D}^{2}$ - to dominate the process. The large parties also hold the vast majority of lower-level agenda-setting officessuch as committee seats, chairs, and rapporteurships - which are also distributed according to party group size. Thus, in the internal agenda-setting process of the Parliament, the large party groups are dominant and have significant abilities to restrict the flow of legislative traffic. These parties are centrist on the first dimension and distinctly pro-integration on the second dimension of conflict (see fig. 2).

Leaders of national governments also have the ability to exercise agenda-setting powers. In addition to agreeing intergovernmental treaties between EU states, national governments also play a role in guiding the ordinary legislative process of EU policy making. For example, the European Council, which is made up of the leaders of national governments, is responsible for setting the "general political direction and priorities" of the Union (European Union 2007). Similarly, Schmidt (2001) argues that the Council of Ministers, which is composed of government ministers from each member state, has significant informal influence over the shape of policies proposed

1. Figure 2 presents the expert survey located positions of the EPGs on these two dimensions for the seventh European Parliament (2009-14).

2. European People's Party; Alliance of Liberals and Democrats for Europe; Progressive Alliance of Socialists and Democrats. by the Commission. While the exact role these bodies play in the agenda-setting process is opaque, it is clear that they have some bearing on which issues arise on the legislative agenda. As Warntjen, Hix, and Crombez (2008) show, preferences for integration in the Council have been positive and stable across a long time period.

Relative to these agenda-setting actors in the Parliament, Commission and Council, the median MEP is more Eurosceptic. Not only are there explicitly anti-integration party groups, but even the centrist EPGs are "far more pro-European than their constituent national parties" (McElroy and Benoit 2011, 163), which makes legislative support for integration within these groups far from guaranteed. ${ }^{3}$

\section{Crisis}

Europe suffered two major waves of economic crisis between 2007 and the present. First, the collapse of the US subprime mortgage market sparked a global financial crisis that caused major difficulties for European banks (Brunnermeier 2009). Second, in 2010, that banking crisis evolved into a sovereign debt crisis, as market fears spread that national governments would be unable to meet their guarantees to failing banks (Lane 2012). These crises were extraordinarily damaging for EU countries, causing large declines in gross domestic product (GDP), foreign direct investment, global exports and commodity prices, and dramatic increases in unemployment. There was also considerable deterioration in the public finances of EU national governments, with several countries brought to the brink of sovereign default and forced to rely on bailouts from their European neighbors (Paulo 2011).

These crises demonstrated that EU economic policies and institutions, constructed in an extended period of growth, were ill suited to times of economic turmoil. For example, the banking crisis revealed that European banks, which had become large and overleveraged, represented a more significant risk to the stability of the financial system than was previously understood (Acharya, Drechsler, and Schnabl 2011; Alessandri and Haldane 2009). Furthermore, the precrisis regulatory framework was shown to be incapable of coping with the systemic nature of the crisis, providing no tools to respond to the collapse of large international banks (European Commission 2013). As the crisis spread, MEPs were quick to notice the deficiencies in existing regulation. ${ }^{4}$ Similarly, the debt crisis

3. In the specific context of the crisis response Braghiroli $(2015,100)$ suggests that "the EP's stance on the crisis can hardly be defined as unitary."

4. In a debate following the collapse of Lehman Brothers, a prominent member of the EP argued that "the supervision of the financial markets is not working ... the status quo is untenable in the medium and long term." Joesph Daul, EPP MEP, October 8, 2008. 
revealed structural problems with the design of the currency union as a whole. Existing policy to contain imbalances in public debt and current account deficits between Eurozone countries had proven inadequate, as the main rules to encourage fiscal coordination and discipline-enshrined in the Stability and Growth Pact (SGP) - had been consistently broken (ECB 2011; Holinski, Kool, and Muysken 2012; Lane 2012). In the positive economic conditions in which the SGP was formed, governments were able to fund excessive budget deficits relatively cheaply, by borrowing from the international bond markets (De Grauwe 2011). However, as the crisis hit, and these markets dried up, the sustainability of these policies was called into question. As one MEP argued: "The economic and financial crisis has revealed all too clearly the shortcomings and weaknesses of the existing instruments and methods for coordinating economic and currency policy."

\section{Theory}

Our theoretical model of how the crisis influenced voting in the European Parliament starts from this observation that the crisis dramatically reduced the attractiveness of existing status quo policies to legislators and opened a window of opportunity for economic policy change. When voting on policies, legislators operate in specific economic and political contexts that inform their perception of different policy options, and they prefer to select alternatives that are well suited to current conditions. At the time of adoption, policy will be written to "fit" the external circumstances relatively well, but policy is static and can only be changed with further legislative effort. External circumstances, by contrast, are dynamic and undergo exogenous changes so that as time passes the degree to which a given policy remains effective may decline. In normal times, slowly changing external circumstances open up only limited opportunities to overcome coalitions opposed to policy change. A crisis constitutes a dramatic change to external conditions which leads to a large decrease in the efficacy of extant policy. This makes legislators much more inclined to accept alternatives to the status quo, which (in expectation) will be better suited to the changed environment.

The form that these alternative policies take depends on which actors control the agenda-setting process. Actors who monopolize proposal power are able to exploit the fact that the status quo has become unpopular in order to pass policy that previously would have failed to secure a majority. Romer and Rosenthal (1978) show that agenda setters with the ability to make take-it-or-leave-it offers can exploit situations in which the status quo is unattractive.

5. Richard Seeber, EPP MEP, October 20, 2010.
"The worse the status quo, the greater this threat and, consequently, the greater the gain to the setter from being able to propose the alternative" (Romer and Rosenthal 1978, 3536). In the Romer and Rosenthal model a status quo is "worse" when it is in an extreme position in the policy space, and others have considered the effects of an exogenous shock to the spatial position of the status quo (Tsebelis 2002). However, for modeling a political crisis, we believe it makes more sense to think of the status quo as worse in nonspatial terms. A crisis entails a sudden change to the external conditions in which existing policies operate, rather than an exogenous change to the extent to which those policies are on the political left or right, or the extent to which they are integrationist or not. We therefore build on these previous models by modeling a crisis not as an exogenous shift in the position of existing policy but rather as a nonspatial shock to the status quo. ${ }^{6}$

To motivate this nonspatial conceptualization of a crisis, consider the example of a typical US state with constitutional requirement to balance its budget each year. The United States enters recession, creating a shortfall in the state budget, which is a situation where the current bundle of taxation and spending policies are poorly suited to the new economic environment as they would lead to a government shutdown. The legislators then face a range of choices that would avert this bad outcome: they could move policy to the right by primarily or exclusively reducing services, to the left by primarily or exclusively increasing taxes, or keep it where it is with some balance of the two. Legislators agree that current levels of taxation and spending no longer "fit" the conditions, but they disagree over the appropriate policy response. In such a situation, all legislators will be more willing (to a degree dependent on how much they want to avoid a shutdown) to tolerate deviations from their ideal tax and spend policies in order to replace the untenable status quo. Existing policy is not itself affected by the crisis in a left-right spatial sense: it is the same policy it was before the crisis.

Here we will use the widely used term "valence" to refer to this nonspatial quality of policy. In models of elections, valence is understood to reflect voters' preferences for universally valued candidate characteristics such as integrity, competence, and ability to provide local public goods. ${ }^{7}$ In our model, valence is the degree to which policy is well suited to external conditions and can be alternatively understood as

6. We discuss alternative ways of modeling a crisis in more detail below, and in app. sec. A9.

7. See, e.g., Adams et al. (2011), Ansolabehere and Snyder (2000), Ashworth and Bueno de Mesquita (2009), Enelow and Hinich (1982), and Groseclose (2001). 
the reduced form of an additional policy dimension on which there is universal agreement. ${ }^{8}$ In our empirical analysis we exploit the fact that only certain status quo policies are affected by the crisis in order to identify changes in legislative behavior between crisis and noncrisis periods.

Combining this understanding of crisis politics with the general preference structure of the European Parliament leads us to consider a model where legislators have preferences over locations in two general policy dimensions, $x_{1}$ and $x_{2}$, and also prefer policies with higher valence $v .^{9}$ This yields quadratic-loss random utility functions for the proposal and alternative:

$$
\begin{aligned}
& u_{i q}=-\left(x_{i 1}-x_{q 1}\right)^{2}-\left(x_{i 2}-x_{q 2}\right)^{2}+v_{q}+e_{i q}, \\
& u_{i p}=-\left(x_{i 1}-x_{p 1}\right)^{2}-\left(x_{i 2}-x_{p 2}\right)^{2}+v_{p}+e_{i p},
\end{aligned}
$$

where we define the valence terms as follows:

$$
\begin{gathered}
v_{p}=0 \\
v_{q} \begin{cases}=0 & \text { absent a crisis } \\
<0 & \text { during a crisis }\end{cases}
\end{gathered}
$$

In the absence of a crisis, the valence of the status quo and the valence of new policy are equal $\left(v_{p}=v_{q}\right)$. A negative "shock" to the valence of the status quo occurs when a crisis dramatically changes external conditions, resulting in a smaller value of $v_{q}$ such that, in expectation, $v_{p}>v_{q}$. As legislators preferences over valence are identical, this formulation captures the central intuition: shocks to the valence dimension are painful for everyone. The crisis negatively affects legislators evaluations of the status quo, regardless of their ideological disagreements on other spatial dimensions.

Example cases of voting under these utilities are depicted in figure 1. Consider a situation where there is no valence gap between the status quo and the proposal (fig. $1 A, v_{q}=$ $\left.v_{p}\right)$. Absent a crisis, voting accords to a simple spatial model. Legislators vote "yea" ' if their own ideal point is closer to the proposal $(p)$ than it is to the status quo $(q)$ and "nay" otherwise. The dashed cutline separates "yeas" from "nays." The

8. Thus, a valence shock can be alternatively understood as a shock to the spatial position of the status quo that moves policy to a position far outside the range of legislator preferences on this additional dimension, see app. sec. A2 for a derivation showing these models are equivalent.

9. In app. sec. A3 we generalize the analysis by considering a "1D plus valence" model that also captures the central intuition that agenda-setters secure more preferable policy outcomes during a crisis. However, in addition to being a poor match to EP politics, the $1 \mathrm{D}$ model predicts that voting coalitions remain unchanged while the policy proposal positions change between crisis and noncrisis periods. The former are far more easily measured than the latter. dotted circle represents a hypothetical "winset"10 - the set of policies that would defeat the status quo in pairwise comparison. Policies located within the winset will defeat $q$ in an up-or-down vote, and policies located outside the winset will fail. The proposal $p$ is determined by the agenda setter (AS), who makes a take-it-or-leave-it proposal that is as close as possible to her own ideal point, within the constraint that the policy will be approved by a majority vote (i.e., within the winset).

Here, the agenda setter is located at a relatively moderate position on the first dimension but an extreme positive position in the second dimension, so the proposal is close to the top of the winset. Given the illustrative winset shown, the proposal mostly moves policy from left to right, rather than south to north. Because of this, the cutline falls nearly vertically, and the "yea" coalition is formed of legislators on the right side of the policy space.

Consider now the crisis case $\left(v_{q}<v_{p}\right)$, where we temporarily hold fixed the positions of $q$ and $p$ (fig. $1 B$ ). The main implication of the decline in $v_{q}$ is that any given legislator is willing to accept a broader range of policies because the ideological cost of accepting a more distant $p$ is compensated for by replacing the low-valence $q$. The decline in $v_{q}$ therefore leads some legislators to vote for $p$ despite their relative proximity to $q$, resulting in a larger coalition of support for $p$ during the crisis. This is depicted by the leftward shift of the cutline. If the proposed policy $p$ is held fixed, a crisis will lead to a larger "yea" coalition than in the noncrisis period.

However, because more policies are able to defeat $q$ (the winset expands), the agenda setter can propose a policy closer to her own ideal point that will still win a majority of support. This means that the agenda setter can propose $p^{\prime}$ instead of $p$ (fig. 1C). As $p^{\prime}$ is within the enlarged winset it is approved by the legislature, whereas in the equal valence scenario it would have been rejected, and the agenda setter obtains a policy outcome that would not have been possible in the absence of the crisis. These figures make clear the agenda setter's advantage during crisis periods. The worse a valence shock (i.e., the lower $v_{q}$ ), the larger the winset grows, and thus the more discretion the agenda setter has over policy.

\section{Predictions: Policy response}

The first implication of the model is that agenda setters will propose and obtain policies closer to their ideal points during crises. Legislators take the broader policy-making environment into account when deciding on policy, and while always

10. Analytically deriving the winset is not possible without first specifying the $2 \mathrm{D}$ preference distribution of legislators. However, an illustrative version is sufficient for our purposes here. 


$$
\text { A } v_{q}=v_{p}
$$

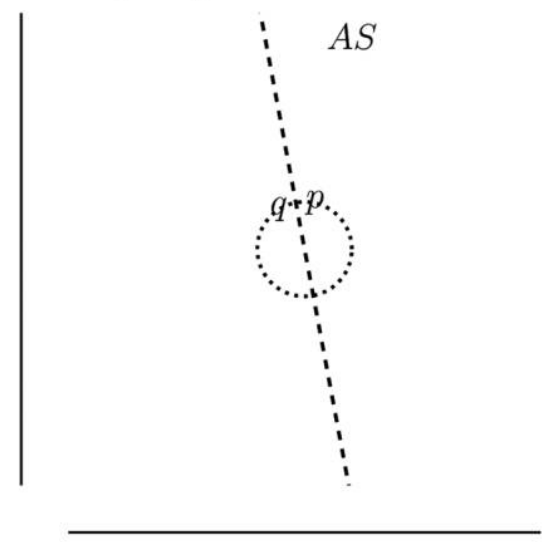

\section{B $v_{q}<v_{p}$}

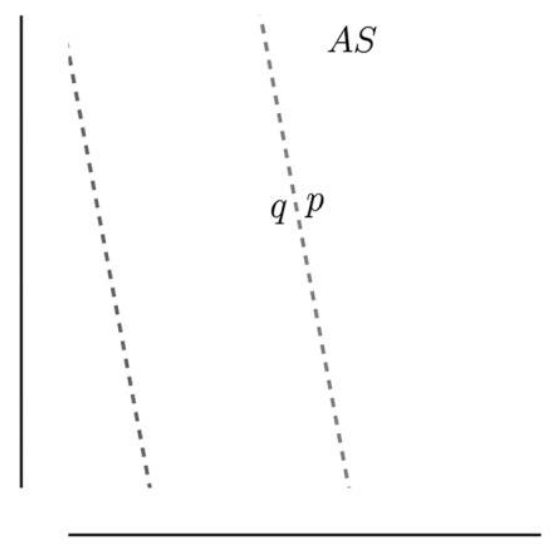

C $v_{q}<v_{p}$

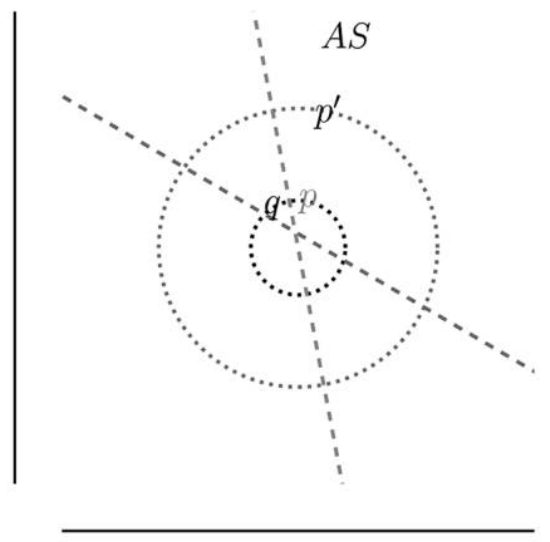

Figure 1. Crises, legislative voting, and agenda setting in two dimensions. $A$, In the absence of a crisis, voting collapses to a simple spatial model, with legislators voting for the proposal $p$ if they are to the right of the cutline, or against the proposal otherwise. $B$, If the status quo $q$ receives a negative valence shock, but the proposed policy is fixed at $p$, then the cutline will shift to the left, indicating that some legislators who previously would have voted against $p$, now would vote "yea." $C$, In equilibrium, the agenda-setting actor (AS) will exploit this tolerance to propose policy ( $\left.p^{\prime}\right)$ that better represents her interests. The agenda setter "makes an opportunity out of the crisis." We can identify the effects of such a proposal in two-dimensional voting patterns, as the cutline rotates in the direction of the ideal point of the agenda setter.

sensitive to deviations from their own policy preferences, they are also concerned with adopting policies that are congruent with current conditions. This means that when crises cause sudden changes in the external environment, existing policies (the status quo) become less attractive and make legislators more receptive to alternative proposals. The model therefore provides microfoundations for the idea that crises represent "an opportunity to be exploited" by agenda-setting actors.

Our decision to model crises as a nonspatial valence shock distinguishes our argument from other plausible mechanisms that could link a crisis to changes in legislative behavior. First, one could model an exogenous shock as a sudden movement of the status quo in the policy space (Tsebelis 2002). Second, one might also model the effects of a crisis as an exogenous shift in the preferences of legislators. The key difference between these models of crisis and our valence-shock model is that in the latter, the worse the valence of the status quo, the greater the discretion of the agenda setter to move policy in any direction. This contrasts with modeling a crisis as a spatial shock - either to preferences or to the position of the status quo - where the winset expands in directions determined by the direction of the shock, meaning that agenda setters benefit only under certain conditions. We prefer to conceptualize a political crisis as a nonspatial shock because this better approximates our intuitive understanding of a crisis: whereas spatial shocks imply that some actors prefer the crisis, nonspatial exogenous shocks make the status quo worse for everyone. $^{11}$

11. In app. sec. A9 we detail the conditions under which spatial and nonspatial shocks result in equivalent observable implications, and demonstrate that it is not necessary to accept the "valence-shock" aspect of our model in order to accept most of our argument as to how crises empower agenda setters. 
In the context of the European Union, the model implies that a relatively wide range of policy options could plausibly have won majority support in the European Parliament during the crisis period, as MEPs should have been willing to make ideological compromises in order to replace defunct policy. Although the policies adopted during the crisis had a distinctive ideological profile, two broad policy responses, which proposed opposing shifts along the integration dimension, were in fact discussed. Pro-integrationist actors argued for the integration of banking regulation, the creation of new EU financial oversight institutions, and further empowerment of existing institutions to enforce fiscal discipline on member states. Proponents of this integrationist response included the European Commission president, José Manuel Barroso, who argued that the EU response to the crisis "must be far reaching reform.... Europe's contribution must be a big step for an ever closer, ever stronger Union" (Barroso 2013). An alternate policy response, supported largely by Eurosceptic actors, focused on streamlining the European institutions to make them more competitive, safeguarding national regulatory powers, and "repatriating" powers from Brussels back to the national level. British Prime Minister David Cameron made this argument in 2013 by emphasizing that future EU reforms ought not to include "an insistence on a one size fits all approach which implies that all countries want the same level of integration. The fact is that they don't and we shouldn't assert that they do" (Cameron 2013). Overall, while the crisis led to dissatisfaction with the status quo across the political spectrum, there was substantial disagreement about the ideal strategy for resolving deficient policy, disagreement that largely reflected the preexisting dimensions of disagreement over EU integration.

This alternate policy response never reached the floor of the European Parliament because agenda setters in the European Parliament are uniformly pro-integration. ${ }^{12}$ It is unambiguous that integrationist legislation passed during this period. The legislative response to the financial crisis included many pol-

12. That the main agenda-setters worked together to propose integrationist responses to the crisis is clear from the parliamentary debates of the period. For example, in a parliamentary debate on the "six-pack," András Kármán emphasized that both the European Commission and the leaders of national governments were united by a desire to reform the economic governance of the EU: "It was not the individual decision of the Presidency to designate this file as the top priority. The Commission's initiative has also been supported by the Heads of State and Government of the 27 Member States." (Kármán 2011) Similarly, the rapporteur for the proposal to establish new European institutions for financial supervision highlighted the consensus among the mainstream EPG leaders: "Parliament is firmly committed, politically committed, to European supervision, and I believe that there is great consensus on this among all political groupings" (de Vigo 2010). icies that transferred significant powers from the national to the European level. The European Union instigated a major set of banking reforms, including: a common rulebook for banking practice; the establishment of a Single Supervisory Mechanism (SSM) for the oversight of risk in the banking system; a Single Resolution Mechanism (SRM), which makes Eurozone governments jointly responsible for the solvency of private banks; and a host of new institutions that aim to limit systemic risk. The European Commission acquired dramatically increased powers under the new fiscal framework, the harmonization of banking standards directly affects national law, and the new institutions can be seen as quasi-federal supervisory authorities (Lannoo 2011, 2).

The response to the debt crisis was perhaps even more integrationist. The most high-profile changes included legislation to increase the Commission's ability to scrutinize member-state finances; a legislative "six pack," which bolsters the Stability and Growth Pact by establishing fiscal goals to which memberstates must converge; and the creation of the European Stability Mechanism (ESM), a permanent rescue facility for the Eurozone area. Again, these reforms entail a significant deepening of integration in economic affairs, empowering supranational actors such as the Commission and the European Central Bank, and transferring sensitive policy competences to the European level. In sum, integrationist policies relating to sovereign finances, macroeconomic coordination and banking reform were proposed by the European Commission and were adopted by legislators in the European Parliament. ${ }^{13}$

\section{Predictions: Voting coalitions}

If our theoretical model captures the dynamics of the EU case, there is a second implication, which concerns how vot-

13. We note that the European Parliament did not play a central role in all parts of the EU's crisis response. For example, the Parliament was not required to approve the "Fiscal Compact," a high profile treaty which introduced stricter budgetary surveillance and discipline within the eurozone area. As Tsebelis and Hahm (2014) suggest, the mechanism through which this treaty was adopted can be explained by reference to the changing dimensionality of the policy space between disagreeing member states, rather than a shift to the dimensions of contestation in the Parliament. Nevertheless, a great deal of important crisis-related legislation required passage under the ordinary legislative (codecision) procedure in which the Parliament acts as a full co-legislator with the Council. For example, the "six pack," "two pack," and the establishment of the European Systemic Risk Board (ESRB), the European Securities and Markets Authority (ESMA) and the European Banking Authority (EBA) were all dealt with under the codecision procedure. Although the Fiscal Compact was certainly an important element to the crisis-response, it would have been largely ineffective without these extensive reforms to the EU's economic governance architecture. These were major integrating measures that the EP could have blocked, and our argument addresses why the EP did not do so. 
ing coalitions in the two-dimensional space of EU politics ought to have changed in response to a crisis. The main observable implication of the model is apparent in figure $1 C$, where the cutline separating the "yea" from the "nay" voters rotates after the valence shock to become closer to horizontal. The more "northerly" the policy proposal relative to the status quo, the more legislators will vote based on their preferences regarding the second dimension rather than the first, leading to a more horizontal cutline between the voting coalitions. Extending this logic to the general case, because a crisis enables the agenda setter to move policy toward her ideal point to a greater degree, the dimension of observed political disagreement will shift toward the dimension along which the agenda setter differs most from the typical legislator. ${ }^{14}$

As the preference structure of the European Parliament and the location of agenda-setting actors in the preferences space reflects the theoretical structure we previously used to illustrate our model in figure 1, we expect a similar rotation of the cutlines in the European Parliament in response to the financial crisis. If agenda setters proposed more pro-integration policy solutions, the cutlines separating voting coalitions should have been increasingly horizontal, dividing pro- and anti-European MEPs, rather than vertical, dividing right and left MEPs. ${ }^{15}$

We are therefore interested in assessing the degree to which the cutlines of crisis-related EP votes tend toward horizontal. We denote the angle of the cutline of a vote as $\varphi_{j}$, and define this angle over an arc of $2 \pi$ such that it equals zero when the cutline is horizontal. ${ }^{16}$ Figure 2 gives a graphical depiction of

14. Our expectations regarding the change to voting coalitions that result from a valence shock rely on the assumption that individual legislators vote spatially, and are not subject to significant party discipline. This is reasonable in the case of the EP, where party discipline is notoriously weak. If party discipline were stronger and parties voted spatially, the same logic would apply but at the level of parties rather than individual legislators.

15. One possible objection is that the "take-it-or-leave-it" agenda power assumed by our model is unrealistic in the EP, where floor amendments are permissible. If amendments can be used to rein in proposals that are too integrationist, while still replacing the status quo with a higher valence proposal, then pro-integration agenda setters would not profit from increased discretion during a crisis. However, evidence strongly suggests that amendments tend to change policy on the left-right dimension of conflict but not the integrationist dimension (Hix et al. 2007; Kreppel 2000; Kreppel and Hix 2003; Kreppel and Tsebelis 1999). There are technical limitations to proposing such amendments, as doing so would require legislators to propose fundamentally reformed institutional structures. This would require significant legislative resources, expertise, and drafting time. The anti-integrationist party groups (the actors with an incentive to propose such amendments) are resource-poor in comparison with the larger groups and the European Commission. Thus, in the context of the EP, it is unlikely that the power of agenda setters is significantly diminished by the availability of amendments.

16. We formally derive the relationship between the cutline angle and the extent to which policy is moving in the second relative to the first dimension in the supporting information. different values for $\varphi$. In the top-left quadrant, when $\varphi=0$, the coalition of yes voters is pro-integration. The top-right and bottom-left quadrants demonstrate the necessity for the definition of $\varphi$ over an arc of $2 \pi$. In both cases, the cutline is vertical, separating left-wing from right-wing voters, but when $\varphi=\pi / 2$, the right-wing voters are voting for the vote, and the left-wing voters are voting against. By contrast, when $\varphi=-\pi / 2$, it is the left coalition that is on the yes side of the vote. The final quadrant shows the cutline (with $\varphi=\pi / 4$ ) where the yes coalition is pro-integration but right-leaning.

In terms of $\varphi_{j}$, we can characterize the average tendency of coalitions to align with yes votes among pro-integration MEPs using the mean absolute angular deviation (MAAD) from zero:

$$
\operatorname{MAAD}=\frac{1}{M} \sum_{j=1}^{M}\left|\varphi_{j}\right| .
$$

The closer to zero the MAAD is, the greater the tendency of votes to have yes voters among pro-integration MEPs and no voters among anti-integration MEPs (of both left and right).

Our argument suggests that when a crisis occurs, the valence of existing policy will decline, leading to more integrationist policy proposals, and a shift in the distribution of the cutlines. However, crucial to our argument is that we only expect MAAD to decline in policy areas that are affected by the crisis. Our argument is policy-domain specific, as it is only status quo policies in crisis-related areas that will receive a valence shock, and so only in votes on these issues that we expect to observe a rotation of cutlines. This yields a testable prediction that has the form of a differences-in-differences: we expect that after the onset of the crisis, cutlines will shift toward horizontal in crisis-relevant policy areas relative to noncrisis-relevant policy areas.

\section{DATA AND METHODS}

Our theoretical model, as applied to the European Parliament, has implications for the voting behavior we observe during the crisis relative to the counterfactual voting behavior we would have observed absent the crisis. Since we cannot observe MEPs' votes in the absence of the crisis, the task of our empirical analysis is to construct the most plausible estimate we can of the counterfactual. We do this by using legislative summary texts to identify legislation in the precrisis period that addresses the same legislative topics as the legislation that we can observe is crisis related in the crisis period. Once we have constructed the synthetic control group of comparable legislation, we can compare voting patterns in the precrisis and post-crisis period on legislation that is as similar as possible in the issues it addresses. 


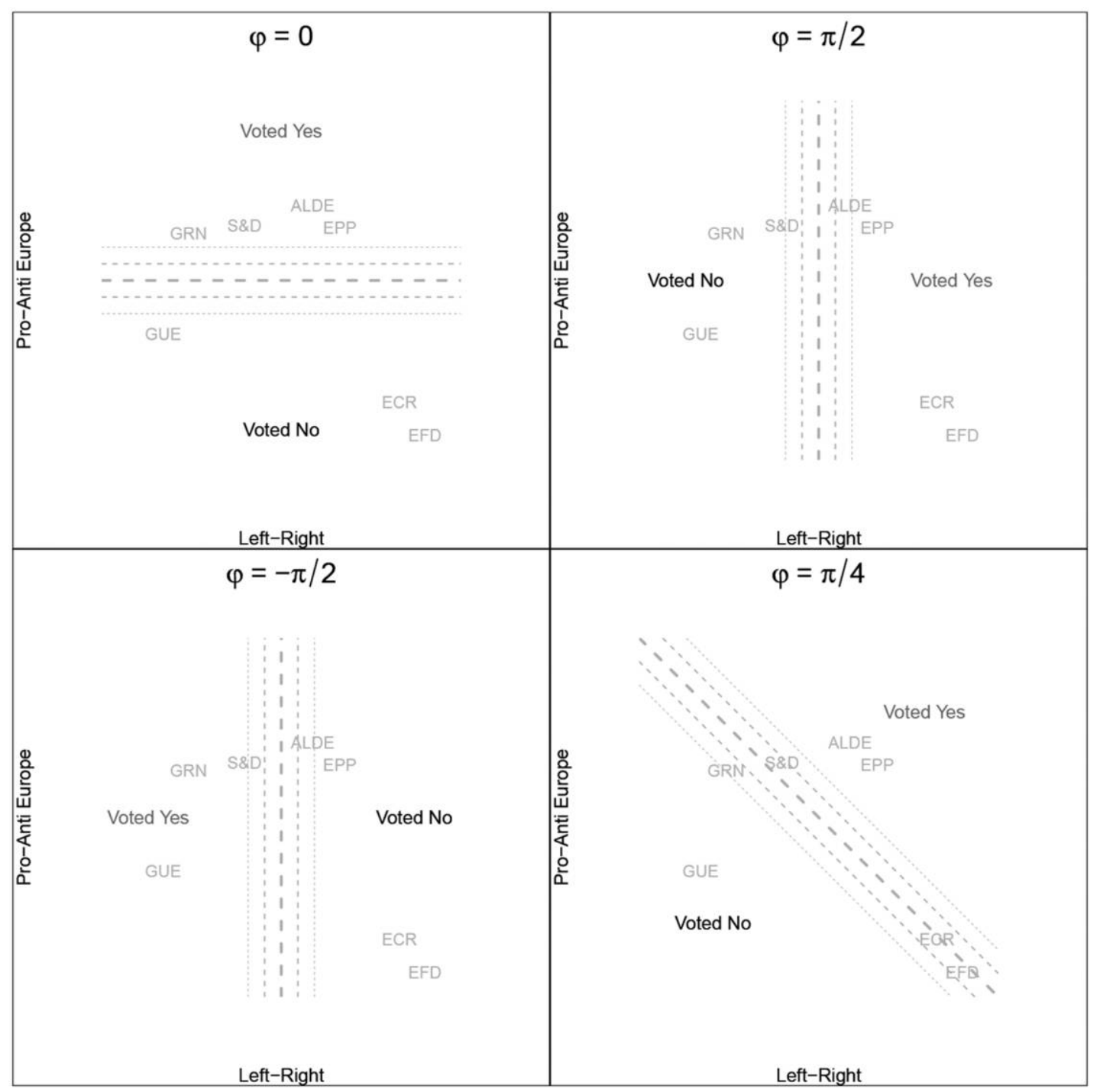

Figure 2. Voting coalitions for different values of $\varphi$. The model we present predicts that more votes will result in a situation similar to the top-left quadrant, where $\varphi=0$ and the coalition is pro-integration, in the post-crisis period.

\section{Scaling votes}

We collect voting records for legislators in the European Parliament from www.votewatch.eu, which documents every recorded vote in the EP. We collect all votes from the sixth and seventh European Parliaments (2004-14), therefore including a period before and after the emergence of the crisis. In order to make estimated cutlines for EP6 and EP7 comparable, it is necessary to jointly estimate preferences over both parliaments. We combine the roll-call votes taken in EP6 and EP7, holding the preferences of individual MEPs serving in both constant. To ensure that we can distinguish left-right political preferences from pro-anti integration preferences, it is necessary to use some kind of auxiliary information to orient the latent preference space along those axes. To identify these dimensions, we implement a hierarchical 2D ideal point estimator in Stan (Stan Development Team 2014) using expert survey data (McElroy and Benoit 2011) to locate the average positions of party groups in EP6 and EP7. These locations form priors over the average positions of MEPs in each of the two dimensions, with the party group priors for both EP6 and EP7 informing the priors of MEPs who served in both Parliaments. For further details of the ideal point estimation and the derivation of how the cut angles $\varphi_{j}$ are calculated from the estimates, see section A4 of the appendix, available online.

\section{Identifying crisis-relevant and non-crisis- relevant votes}

Our model implies that there will be a difference in the distribution of the $\varphi_{j}$ between votes that relate to the crisis and votes that do not. We therefore require a method for distin- 
guishing between crisis-relevant and non-crisis-relevant votes. ${ }^{17}$ To begin, for each vote we collect a legislative summary text from the EP website. ${ }^{18}$ The summaries give a synopsis of the purpose, background, and content of legislation under discussion and thus provide salient textual information for classification. ${ }^{19}$ An example text is provided in the appendix (sec. A1). We search the EP7 summaries for the presence or absence of five key phrases that indicate direct relevance to the crisis: "financial crisis," "economic crisis," "sovereign debt crisis," "euro crisis," and "Eurozone crisis." This search returns a binary classification of the "crisis relevance" of a vote, and of the 6,916 votes held during EP7, our selection procedure codes 1,071 as "crisis-relevant."

In accordance with our theoretical model, votes in EP7 identified as crisis-relevant by this key phrase coding were marked by significantly ( $t=-6.8$, assuming independence) and substantially (about 18\%) lower values of MAAD than non-crisis-relevant votes during the same period. That is, during the crisis period, broadly defined as the entirety of EP7, votes on crisis-relevant legislation divided MEPs more along pro-anti lines than did votes on non-crisis-relevant legislation. However, this difference between crisis-relevant and non-crisis-relevant votes in EP7 may reflect a preexisting feature of EP disagreement across different policy domains. Are these differences in voting patterns part of the preexisting structure of voting on economic and finance versus other issues, or a change in voting structure that resulted from the crisis?

17. One approach would be to classify votes according to their committee of origin so that, e.g., votes on reports originating from the Economic and Monetary Affairs (ECON) committee could be crisis-relevant, and all other votes nonrelevant. However, relying on a simple committee categorization is problematic. ECON reports include a diverse selection of legislation, only some of which pertain to the crisis. Similarly, many explicitly crisis-related reports did not originate in the ECON committee. For example, an important parliamentary resolution concerning the feasibility of stability bonds (or "Eurobonds") did not originate in the ECON committee. Such an approach would yield a coding that, at best, only roughly approximated our classification of interest. Another approach would be to manually code votes from EP6 and EP7 that we deem to be crisis related; however, this would require a great deal of subjective judgement and require coding many thousands of votes.

18. See http://www.europarl.europa.eu.

19. We opt for the legislative summaries - rather than, e.g., debates or the texts of the proposals themselves-because they are relatively short (the median number of words in each text is 789), and are tightly focused on the topical content of the legislation. While other texts would likely recover a similar classification, legislative speeches would contain considerably more noise than the summaries do, and the clauses of the bills are likely to contain a large proportion of legislative jargon which would be common across bills and would not help us to discriminate between crisis-related and non-crisis-related votes.
Clearly we are unable to observe the relevant counterfactual: what voting would have looked like in EP7 in the absence of a crisis. Therefore, in order to synthesize the most plausible, feasible control group, we look to the preceding European Parliament, where voting coalitions were not subject to the crisis effects that our model contemplates. However, we cannot simply search for mentions of the crisis in EP6 legislative summaries because the crisis had not yet occurred. Instead, we need to identify votes from EP6 that are substantively similar to the crisis-relevant votes we have already identified in EP7. To classify the full set of votes, we develop a novel text classification strategy to estimate the degree to which precrisis votes were "crisis-relevant" so that we can make a fair comparison of votes pre- versus post-crisis. To do this, we train a linear probability classification of EP6 votes using the binary classification of EP7 votes described above as the training data for a model that predicts crisis-relatedness using features of legislative summary texts. The intuition behind our estimation strategy is to use the information contained in the legislative summaries to find votes in EP6 that are about substantively similar issues to the crisis-related votes in EP7 and to use these votes to compare voting coalitions on these issues across the crisis and noncrisis periods. ${ }^{20}$

We begin by estimating topic models (Blei and Lafferty 2006; Roberts et al. 2014) on the corpus of legislative summaries covering every vote in EP6 and EP7. The key quantity of interest recovered from each of these topic models is a matrix of topic proportions that describes the fraction of each legislative summary $d \in\{1,2, \ldots, D\}$ that is from each topic $t \in(1,2, \ldots, T)$. These matrixes offer a highdimensional summary of the substantive content of each vote and give us a basis on which to find thematically similar votes in EP6 and EP7. We then use the topic proportions for the EP7 votes as explanatory variables in "first-stage" linear regressions, where the dependent variable is the manually coded "crisis-relevant" binary classification introduced above. We use the estimated coefficients to generate fitted values, denoted $\hat{\pi}_{j(k d)}$, for all votes in both EP6 and EP7. These values represent the probability that each vote $j$ is crisis-relevant, given the vector of topic proportions for legislative summary $d$ from topic model $k$. The intuition is that the regression coefficients on the topic proportions indicate the thematic elements (the word usage typical of a topic) that predict a vote being crisisrelevant, and the fitted values thus provide a measure for whether the issues addressed in each vote from both EP6 and EP7 were ultimately relevant to the crisis.

20. We give further detail on the construction of our approach in app. sec. A10. 
The above exercise can be completed for topic models with any number of topics or, indeed, using any of the wide variety of topic models that have been developed. Choosing the appropriate number of topics is a common problem in topic modeling, and typical solutions (e.g., Blei, $\mathrm{Ng}$, and Jordan 2003) aim to find the model that best predicts held-out textual data. In our case, we are not interested in predicting text data out of sample but rather in predicting our EP7 classification of "crisis-relevant" votes. Thus, we fit all $K=98$ integer topic counts from 3 to 100 and then use several approaches to assess which yields the most predictive first-stage regression for crisis-related votes in EP7. For each of the first-stage regressions, we calculate $\mathrm{BIC}, \mathrm{AIC}$, and adjusted $R^{2}$. AIC and adjusted $R^{2}$ agree on the 62-topic model, while BIC (which includes a greater penalty for additional parameters) favors the 29-topic model (the second-best model under AIC and adjusted $\left.R^{2}\right){ }^{21}$

To complement this model selection based on fit to the EP7 summaries, we have also compared the model based predictions of whether an EP6 summary is crisis-related to human judgements of crisis relatedness for a hand-coded random subset of 200 summaries, coded by both authors. The goal of this exercise is to establish whether the text based classification of EP6 summaries correlates with human judgments of the types of issues that were likely to become pertinent to the crisis once it began. We provide full details of this validation exercise in the appendix (sec. A6), however it indicates that topic models with 20-40 topics tend to yield estimates of crisisrelatedness that are more highly associated with human coding than those with higher topic counts. This is consistent with more general results on human validation of topic models (Chang et al. 2009). Therefore, we proceed in this paper with the 29-topic model and present the (similar) results using the 62-topic and other models in the appendix.

Before turning to our main results, we assess the face validity of our procedure. Our primary concern is obtaining good estimates for which EP6 votes were in policy areas that were to become relevant to the crisis once it arrived. We can directly examine the votes from both EP6 and EP7 that our model estimates to have high crisis-relevant probabilities $\left(\hat{\pi}_{j}\right)$. Table A1 (tables A1-A6 available online) presents the titles of the top 20 crisis-relevant texts from the 29 topic model, from both parliamentary terms. ${ }^{22}$ As expected, the classification procedure successfully recovers the explicitly crisisrelated votes from EP7. Many of the well-known economic

21. In fig. A3 we present the three fit statistics for all 98 models. 22. An equivalent table, for the 62 topic model, is given in app. sec. A8. reforms - such as the "six pack," the "two pack," and the European Semester-feature in the EP7 list. The EP6 voteswhich occurred before the crisis - are also all directly related to the issues that became increasingly significant after 2008 . Votes relating to the strengthening of national budgetary positions, public finances, financial markets, credit rating agencies, and the common currency all feature prominently at the top of the EP6 list. The procedure is not simply picking up votes from late 2008 and early 2009 in EP6, as several of the vote titles include the year in which they were voted upon, and they cover the whole of the EP6 period..$^{23}$ In general, these results suggest that our classification procedure works remarkably well, and that our synthetic control group is a reasonable basis for comparison.

In addition, if our procedure is successfully identifying crisis-relevant summaries, then the coefficient estimates from the first-stage models will also be informative, as we would expect those topics relating to financial and economic affairs to be strongly associated with our key phrase search classification in EP7. Figure A6 (figs. A1-A8 available online), which presents the estimated first-stage coefficients for the topic proportions from the 29 topic model alongside their associated topic labels, ${ }^{24}$ confirms this expectation: the two topics that are most predictive of our key phrase search classification (i.e., those with the largest positive coefficients in the first stage) are "econom;financi;member;state" and "financi;credit;bank;author."

Throughout the analysis we use the crisis-relevant fitted values for both EP6 and EP7 votes, rather than relying on the discrete categorization for EP7 that is produced by our key phrase search. There are two rationales for doing this. First, simply for comparability between the two periods: if we are using fitted values in EP6 we should also do so in EP7 to minimize differential measurement error. Second, although the key phrase search provides a quick classification of crisis relevance, it is unlikely to perfectly separate crisis-relevant legislation from non-crisis-relevant legislation, even within the crisis period. If an EP7 summary does not explicitly mention any of the phrases we include in the search, it will be counted as irrelevant to the crisis. Thus, for example, even if the subject matter of the legislation is tightly connected to matters of finance, banking, and economic governance, if our search terms are absent from the summary, our search will return a false negative-a sum-

23. Figure A7 shows that our text model recovers crisis-related votes across the entire time period but, reassuringly, records a peak in crisisrelevant legislation in 2011-12.

24. The topic labels are constituted of the of the top four highest probability words characterizing each topic. 
mary that should be coded as crisis-relevant but is not. We should also be concerned by false-positive results returned by such a search. For example, a legislative summary may include one of the phrases we include in our search but only be tangentially related to the economic crisis that we wish to study.

Our topic-modeling procedure helps to overcome these difficulties, as we treat the classification provided by the key phrase search as training data for discovering the topics that are generally associated with our crisis search terms. These training data we have are noisy (because of the potential for false-negative and false-positive classifications), but by regressing the key phrase search classification on the topic proportions for each summary produced by our topic models we are able to identify the topics that are consistently associated with crisis legislation. Our approach therefore uses the manual coding as a way of finding features (topics) that are common across many different possible crisis-related legislation texts.

Table A3 shows that the summaries that have high fitted values from the topic model analysis but lack the key phrases used in our binary classification include several high-profile pieces of crisis legislation, while those which have low fitted values but have those phrases are indeed weakly related to the crisis, which demonstrates the benefits of using the topic proportions to produce fitted values of crisis relevance. This validity check further justifies moving beyond a simple key phrase search to define our treatment and control groups. A key phrase search is impossible in the precrisis period, as no legislative summary could make explicit mention of the crisis before the crisis occurred. Our topic-model classifier allows us to compare the voting coalitions that form on legislation on thematically similar topics both before and after the crisis commenced. In addition, even within the crisis period there is good reason to prefer the text-based classifier over a simple search for key phrases.

\section{Differences-in-differences results}

Having selected the best fitting first-stage model, we use the fitted values of crisis relevance as explanatory variables in a second-stage linear regression of the following form:

$$
\left|\varphi_{j(d)}\right|=\sum_{t}\left(\alpha_{t}+\beta_{t} \cdot I_{t} \cdot \hat{\pi}_{j(d)}\right)+\varepsilon_{j(d)},
$$

where $\varphi$ is the angle of the cutline, $I_{t}$ is an indicator variable for whether the vote was taken during a given period $t$, and $\hat{\pi}_{j}$ is the fitted value for the crisis relevance of the vote. Because we are using fitted values for whether the vote was crisis-related, the coefficients $\beta_{t}$ remain estimators of the difference between the MAAD of crisis-related $(\hat{\pi}=1)$ and non-crisis-related $(\hat{\pi}=0)$ votes in that period. Our primary quantities of interest are therefore the $\beta_{t}$ but also the fitted values for non-crisis-related votes $\alpha_{t}$ and for crisis-related votes $\alpha_{t}+\beta_{t}$. The theoretical model directly implies that the fitted values for crisis-related votes should decline once the crisis begins, indicating increasingly pro-versus-anti integration coalitions, rather than left-versus-right coalitions. We also expect to see that decline in the values of the $\beta_{t}$ directly, indicating a shift relative to non-crisis-relevant votes, as evidence against the possibility that some general shift in voting is occurring across all domains. ${ }^{25}$

This approach, which is an unusual application of a twostage least squares estimator, ${ }^{26}$ has two attractive features. First, using the legislative summary texts ensures that we are comparing thematically or topically similar votes across the entire period. This means that if there had always been a difference between how the EP voted on the issues that ultimately become crisis-related and other issues, we will observe a constant difference over time. Second, using the fitted values for crisis-relatedness for both EP6 and EP7, rather than using the binary coding for EP7, enables a fairer comparison of the two periods.

As votes $(j)$ are grouped within texts $(d)$, and the topic mixtures vary only at that group level, a block bootstrap is needed to account for within-text error correlation in the first-stage model (Angrist and Pischke 2008, 315). We jointly bootstrap both regression stages 1,000 times, resampling the texts with replacement, and estimating our quantities of interest at each iteration.

Figure 3 presents the fitted values for crisis-relevant and non-crisis-relevant votes (left panel), and the $\beta_{t}$ coefficients (right panel) from equation (7). ${ }^{27}$ The figure shows that crisisrelated votes in EP6 and the first year of EP7 (June 9, 2009, to June 8,2010 ) were characterized by voting coalitions that were somewhat more left-right than other votes. However, once the political response to the crisis begins in earnest in the middle of 2010, crisis-related votes become more pro-anti than before, and than all other votes occurring at the same time on

25. Our second-stage model (eq. [7]) shares similarities with "leads and lags" models that are commonly used in difference-in-differences designs (Autor 2003). In addition to allowing us to understand how voting coalitions changed over time during the treatment period, this specification also provides an opportunity for us to assess whether voting coalitions on crisisrelevant and non-crisis-relevant legislation were trending differently before the onset of the crisis. Reassuringly, we find no evidence for this.

26. Our first stage does not aim to identify a nonendogenous component of the variation in the treatment variable (crisis vs. noncrisis) but rather to impute treatment for the half of our data where we cannot observe it (EP6).

27. Table A4 presents the full results from the regression. 

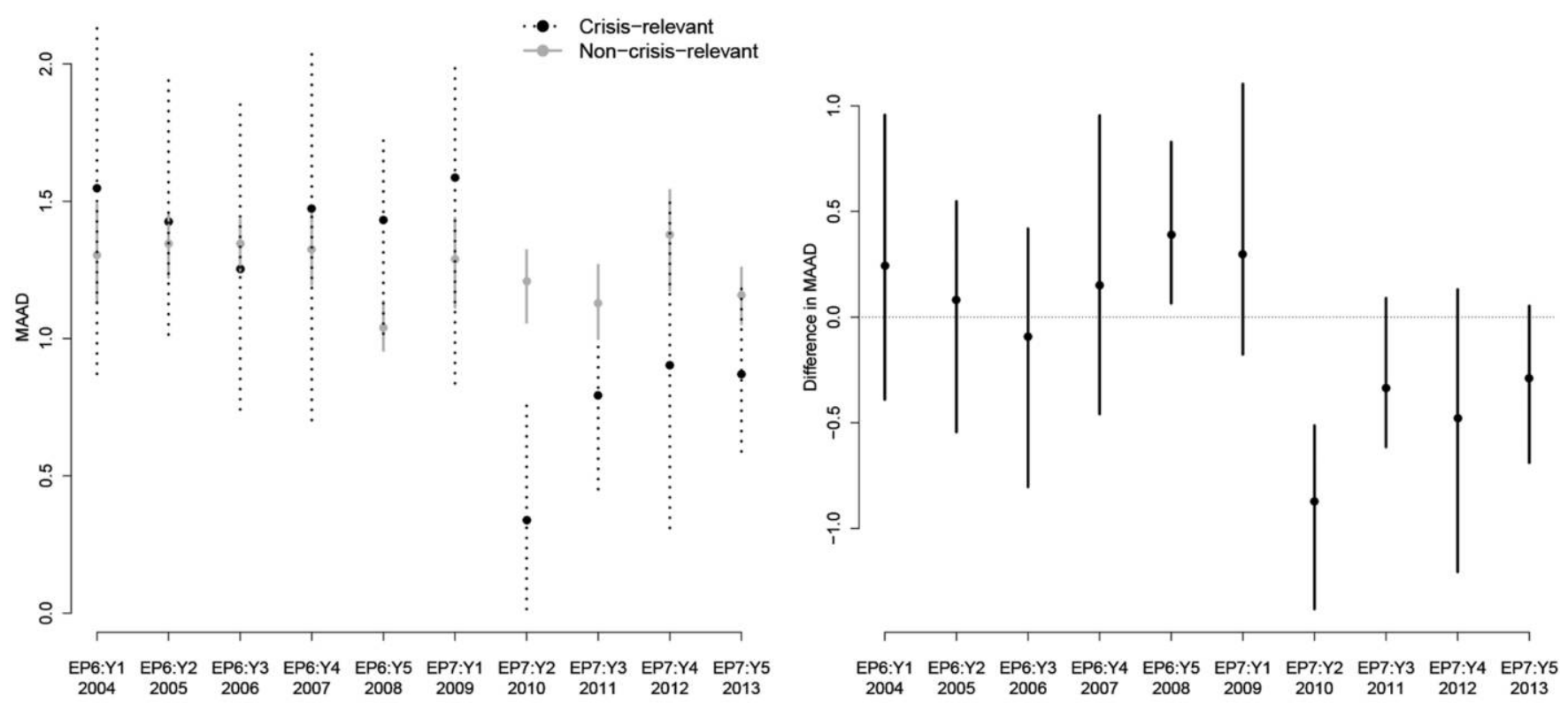

Figure 3. Left, Estimates of the mean absolute angular deviation in crisis-relevant versus non-crisis-relevant votes, for each year in EP6 and EP7 (starting June gth of the labeled year, to align with the 2009 European Parliament elections). Right, Differences between crisis-relevant and non-crisis-relevant votes over the same period.

other issues. The fitted values for the non-crisis-relevant votes (depicted in gray in the left panel of fig. 3) are essentially flat across the study period, suggesting that any change in voting behavior occurred only on crisis-relevant issues.

While the confidence intervals of our $\beta_{t}$ coefficients overlap with zero in later years, the point estimates are negative throughout the crisis-period and clearly indicate a change to the voting coalitions on crisis-relevant votes when compared to the precrisis period. In table A5, we simplify the analysis by comparing voting coalitions on crisis-relevant and non-crisisrelevant votes using two binary codings for the crisis period (rather than the yearly approach we take here). We first treat the crisis period as EP7 versus EP6, and second as post-2010 versus pre-2010. In both specifications, the $\beta$ coefficient we estimate is strongly statistically significant and substantively large. In further specifications presented in table A5, we control for whether a given vote was an amendment or a final passage vote, and for the legislative procedure under which the vote was taken. ${ }^{28}$ In addition, in appendix section A13, we present the main results from all $K$ topic model specifications. Regardless of the model specification, we find that voting coalitions on crisis-relevant legislation during the crisis period are significantly more pro-anti than are those for non-crisisrelevant legislation, relative to the same difference in the noncrisis period.

28. The EP adopts legislation under a variety of different legislative procedures.
Recall that the purpose of creating the synthetic control comparison using EP6 was to rule out the possibility that the kinds of issues that became crisis-relevant had always exhibited relatively pro-anti voting coalitions, even before the crisis. The estimates here suggest otherwise: pro-integration coalitions formed more frequently on crisis-related votes in the post-crisis period relative to non-crisis-related votes, but the opposite was true in the precrisis period. Overall, these results indicate that the coalition structure of voting in the European Parliament changed meaningfully after the onset of the financial crisis in those issue areas that the crisis affected, but not other issue areas. This is what we expected to observe if pro-integration agenda setters were able to exploit the crisis in order to pass integrationist policy that would previously have failed to win a majority of support.

\section{Threats to inference}

One concern with the above analysis is that the change observed in voting behavior could be the result of factors other than the crisis. In particular, two alternative explanations deserve attention. First, changing voting behavior could be the result of a change to the composition of the Parliament after the European elections in 2009. The EP became more fragmented after the election, with smaller parties winning seats from the larger parties, with the implication that fewer pro-integration MEPs were elected. This fragmentation may have lead to more "grand coalition" votes, where the large 
party groups vote together due to their decreased parliamentary strength (Hix 2009).

Second, the European Parliament changed the rules governing which roll-call votes were recorded in EP7. Previously, roll-call votes were recorded only when requested by a political group or one-tenth of the MEPs, meaning that roll-calls were called on approximately one-third of all votes (Carrubba et al. 2006; Hix 2009). However, from June 2009 and the start of EP7, all final legislative votes were automatically taken by roll-call. The effects of roll-call selection in the European Parliament are unclear (Carrubba et al. 2006; Muehlboeck and Yordanova 2012), but it is possible that this change could result in increasingly pro-anti voting coalitions. For example, if roll-call votes had previously been avoided on final votes that were supported by a prointegration coalition, then the rule change would possibly have resulted in increased observations of pro-integration coalitions (and thus lower MAAD scores) in EP7.

While we are unable to entirely discount these alternative explanations that involve the EP6/EP7 changeover, two aspects of our results do not fit with these alternatives. First, we observe a shift in voting behavior one year after the changeover, in 2010 rather than 2009. Second, if either the electoral explanation or the rule change explanation were true, we would expect to observe decreasing MAAD scores across all policy areas rather than just those related to the crisis. The logic of these arguments is that there was some structural or institutional change that affected the entire parliament in 2009, but our analysis uncovers significant change in voting behavior only on crisis-relevant issues. As figure 3 makes clear, there is essentially no change in the average cutline on non-crisis-relevant votes between the two parliaments. Any alternative explanation for our findings must explain the change in behavior over time, the fact that change occurs only in crisis-related votes, and the fact that the change occurred one year after the new parliament began, when the crisis became acute.

A possible objection to the theoretical framing that we have provided for our analysis is that the crisis did not affect the valence of the status quo, but rather influenced the spatial elements of legislators' utility by making MEPs more favorable to increased integration. To account for the fact that observed changes are only in crisis-related policy areas, it would need to be the case that the crisis changed preferences of MEPs in just those areas, which is possible if you take the view that the crisis specifically signaled a need for more integration in only those policy areas. As discussed in our theoretical section, and in section A9 of the appendix, this argument is plausible, but not necessarily incompatible with our own. Both spatial and nonspatial crisis models in this context engage with the idea that the crisis somehow changed the incentives to integrate for MEPs. We think it makes more sense to think about the valence of existing policy, rather than the spatial preferences of legislators for integration, being differentially affected by the crisis, and so we understand the crisis to affect voting behavior through the nonspatial component of utility. In general, however, the most interesting theoretical implications of both our story and the changing preferences story focus on the same counterfactual. Under either account, the primary dimension of conflict in the EP shifted toward pro-anti votes in crisis-relevant areas and policies were passed following the financial crisis that would not have passed in the absence of the crisis.

\section{CONCLUSION}

When José Manuel Barroso, the president of the European Commission, gave his State of the Union speech to the European Parliament in 2013, he argued that, "If we look back and think about what we have done together to unite Europe throughout the crisis, I think it is fair to say that we would never have thought all this possible five years ago" (Barroso 2013). The degree of integration in financial and economic affairs following the crisis was indeed unprecedented, and the argument we have made here is that these policies succeeded because the crisis strengthened the position of pro-integration agenda-setting actors (including Mr. Barroso). Such significant increases in EU competences might not have occurred in the absence of a crisis.

More generally, our model provides microfoundations for the intuition that crises represent "opportunities to be exploited" by industrious agenda setters in the legislative process. Exogenous shocks decrease the efficacy of existing policy in the context of changing real world conditions, and make status quo policies less attractive to all legislators. Because legislators want to replace deficient policy, those with proposal power are able to secure outcomes that would be impossible without a crisis. In contrast to previous literature on crises, we demonstrated how a specific impediment to reform is reduced by exogenous shocks, and also provided predictions about the direction of policy movement during crisis periods which have empirically observable implications for voting patterns which we were able to test.

In the case we examine, pro-integration actors hold the major agenda-setting powers pertaining to financial regulation, and thus in this crisis we expected to observe policy moving toward a more integrationist position. However, given a different distribution of agenda-setting preferences, our model would produce different predictions for the direction of policy movement in the event of a crisis. For example, the unprecedented increase in migrants arriving in Europe since 2014 
has uncovered significant deficiencies in current EU policies. Pro-integration actors have the power to initiate legislation pertaining to migration at the EU level, and the European Commission has drafted legislative proposals that would create a new common border force equipped with powers to overrule national authorities (Commission 2015). However, support for the Commission's proposal is limited amongst member state governments, implying that the agenda-setting power of pro-integration actors is diluted in the area of migration. The relatively equal distribution of proposal powers between EU and national levels will have consequences for the policies that are adopted in response to this crisis. In this case, although there is increasing dissatisfaction with status quo policies, because agenda-setters are not united by common integrationist preferences and proposal powers are diffuse, reforms to border protection policies are likely to be less integrationist than were the reforms to economic policy in the post-financial crash world. As partial evidence in support of this view, several countries within the Schengen free-movement area have recently reintroduced national border controls in an attempt to curb the number of migrants.

Our model may also be a useful heuristic for understanding the legislative effects of other crises, particularly when preexisting policy disagreement is multidimensional. For example, in 1957, Lyndon Johnson, then US Senate majority leader and a powerful agenda setter, recognized that the civil rights bill proposed by President Eisenhower was likely to be filibustered by the Senate southern Democrats. The opposition of these legislators was a significant constraint on executive action and forced Johnson to admit amendments that significantly weakened the enforcement of the bill (Jeong, Miller, and Sened 2009). By 1964, however, Johnson, now president, was able to pass the more robust Civil Rights Act. It is commonly accepted that the racial tensions of the early 1960s gave momentum to the civil rights movement and offered Johnson a window of opportunity in which to pass reform (Keeler 1993, 462). One reading of this is that legislators' preferences shifted toward wanting civil rights legislation, but our model indicates that the marginal legislators could instead have simply recognized that the status-quo was increasingly untenable. As a pro-civil rights agenda setter, Johnson was able to pass reforms that had previously proved intractable in the legislature, shifting patterns of voting toward a northsouth dimension during this period (Poole and Rosenthal 2011, 141-42). Our model has an important implication for the counterfactual: what policies might have been successfully advanced by an anti-civil rights president in the context of the diverse events of the early 1960s, from the "March on Washington" to the Birmingham church bombing? Civil rights legislation might now seem like the obvious policy response, but there is no shortage of historical crises that have been exploited by political agenda setters to achieve less righteous ends. The kinds of crises we model facilitate shifts in any policy direction.

A further theoretical implication is that strategic agenda setters may have an incentive to exaggerate crisis severity in order to maximize their discretion over policy outcomes. There are anecdotal suggestions that certain EU institutions behaved in this manner during the financial crisis. For example, the bond-buying policy of the European Central Bank (ECB) enabled indebted governments to secure enough liquidity to stave off immediate sovereign default but stopped short of providing a blank check which would have fundamentally reassured nervous market actors. Although not itself an agenda-setting actor, the ECB's piecemeal strategy allowed other pro-integration actors such as the Commission to put additional pressure on national leaders and MEPs to agree to reforms of the Eurozone's institutional architecture. As one observer argues, "The central bank cannot directly compel democratically elected leaders to comply with its wishes, but it can refuse to bail their countries out and thereby permit the crisis to pressure them to act" (Bergsten 2012). In short, by emphasizing the deficiencies of existing policy, and exaggerating the likely future trajectory of a crisis, agenda-setting actors can cajole decision makers into passing the policies that they propose. While this logic suggests strong incentives for agenda-setters to exaggerate crisis-severity, their ability to do so will be limited by the credibility of their claims with legislators, the public, and the press.

We describe how crises enable agenda setters to overcome legislative opposition to policy change, but there is no explicit role for voters in our model. An enrichment of the model would be to make legislators subject to voter pressure. However, for this to make a difference to the power of the agendasetter, voters would have to respond to crises by sanctioning some courses of action whilst prohibiting others. More likely, we believe, is that voters' main desire is for politicians to "get something done" in the face of a crisis, thus endowing agendasetting actors with a public mandate that reinforces the legislative mandate they gain in our model. If anything, this will further discourage legislators from voting for the status-quo. As Keeler $(1993,441)$ argues, a sense of public urgency "may serve to override ... caution ... and allows for unusually rapid and uncritical acceptance of reform proposals intended to resolve the crisis." This urgency therefore makes the electorate more permissive of policy proposals and so reinforces agendasetters' discretion. The incorporation of electoral effects into our model may well serve to reinforce the central implication that agenda setters benefit, regardless of what they aim to use the crisis to accomplish. 


\section{ACKNOWLEDGMENTS}

We thank conference participants at the LSE Political Science and Political Economy research seminar, the Midwest Political Science Association conference, the Graduate Conference at Nuffield College and the Formal Theory and Comparative Politics Conference at Washington University in St. Louis. We also thank Simon Hix, Sara Hobolt and Andy Eggers for helpful discussions, as well as the editor and anonymous reviewers for their constructive comments.

\section{REFERENCES}

Acharya, Viral, Itamar Drechsler, and Philipp Schnabl. 2011. "A Pyrrhic Victory? Bank Bailouts and Sovereign Credit Risk." Working paper no. 17136, National Bureau of Economic Research, Cambridge, MA.

Adams, James, Samuel Merrill III, Elizabeth N. Simas, and Walter J. Stone. 2011. "When Candidates Value Good Character: A Spatial Model with Applications to Congressional Elections." Journal of Politics 73 (1): 17-30.

Aldrich, John H., Christopher Gelpi, Peter Feaver, Jason Reifler, and Kristin Thompson Sharp. 2006. "Foreign Policy and the Electoral Connection." Annual Review of Political Science 9:477-502.

Alessandri, Piergiorgio, and Andrew G. Haldane. 2009. "Banking on the State." BIS Review 139:1-20.

Angrist, Joshua D., and Jörn-Steffen Pischke. 2008. Mostly Harmless Econometrics: An Empiricist's Companion. Princeton, NJ: Princeton University Press.

Ansolabehere, Stephen, and James M. Snyder Jr. 2000. "Valence Politics and Equilibrium in Spatial Election Models." Public Choice 103 (3/4): $327-36$.

Ashworth, Scott, and Ethan Bueno de Mesquita. 2009. "Elections with Platform and Valence Competition." Games and Economic Behavior 67 (1): 191-216.

Autor, David H. 2003. "Outsourcing at Will: The Contribution of Unjust Dismissal Doctrine to the Growth of Employment Outsourcing." Iournal of Labor Economics 21 (1): 1-42.

Barroso, José Manuel. 2013. "State of the Union Address." Presented at the European Parliament plenary session, Strasbourg.

Baumgartner, Frank R., Christian Breunig, Christoffer Green-Pedersen, Bryan D. Jones, Peter B. Mortensen, Michiel Nuytemans, and Stefaan Walgrave. 2009. "Punctuated Equilibrium in Comparative Perspective." American Journal of Political Science 53 (3): 603-20.

Baumgartner, Frank R., and Bryan D. Jones, eds. 2002. Policy Dynamics. Chicago: University of Chicago Press.

Bergsten, C. Fred. 2012. "Why the Euro Will Survive: Completing the Continent's Half-Built House." Foreign Affairs 91 (5): 16-22.

Blei, David M., and John D. Lafferty. 2006. "Correlated Topic Models." Presented at the Annual Neural Information Processing Systems Conference, Vancouver.

Blei, David M., Andrew Y. Ng, and Michael I. Jordan. 2003. "Latent Dirichlet Allocation." Journal of Machine Learning Research 3:993-1022.

Blyth, Mark. 2002. Great Transformations: Economic Ideas and Institutional Change in the Twentieth Century New York: Cambridge University Press.

Braghiroli, Stefano. 2015. "An Emerging Divide? Assessing the Impact of the Euro Crisis on the Voting Alignments of the European Parliament." Lournal of Legislative Studies 21 (1): 96-114.

Browne, Eric C., John P. Frendreis, and Dennis W. Gleiber. 1986. "The Process of Cabinet Dissolution: An Exponential Model of Duration and Stability in Western Democracies." American Journal of Political Science 30 (3): 628-50.
Brunnermeier, Markus K. 2009. "Deciphering the Liquidity and Credit Crunch 2007-2008." Lournal of Economic Perspectives 23 (1): 77-100.

Cameron, David. 2013. "EU Speech at Bloomberg." https://www.gov.uk /government/speeches/eu-speech-at-bloomberg.

Carrubba, Clifford J., Matthew Gabel, Lacey Murrah, Ryan Clough, Elizabeth Montgomery, and Rebecca Schambach. 2006. "Off the Record: Unrecorded Legislative Votes, Selection Bias and Roll-Call Vote Analysis." British Journal of Political Science 36 (4): 691-704.

Chang, Jonathon, Jordan Boyd-Graber, Chong Wang, Sean Gerrish, and David M. Blei. 2009. "Reading Tea Leaves: How Humans Interpret Topic Models." Presented at the annual Neural Information Processing Systems conference, Vancouver.

Clark, Tom S. 2006. "Judicial Decision Making during Wartime." Lournal of Empirical Legal Studies 3 (3): 397-419.

Cohen, Jeffrey E. 1982. "The Impact of the Modern Presidency on Presidential Success in the U. S. Congress." Legislative Studies Quarterly 7 (4): 515-32.

Collier, Ruth Berins, and David Collier. 2002. Shaping the Political Arena. Notre Dame, IN: University of Notre Dame Press.

Copeland, Paul, and Scott James. 2014. "Policy Windows, Ambiguity and Commission Entrepreneurship: Explaining the Relaunch of the European Union's Economic Reform Agenda." Lournal of European Public Policy 21 (1): 1-19.

Cortell, Andrew P., and Susan Peterson. 1999. "Altered States: Explaining Domestic Institutional Change." British Journal of Political Science 29 (1): 177-203.

De Grauwe, Paul. 2011. "Managing a Fragile Eurozone." CESifo Forum 2:40-45.

De Vigo, Î́nigo M. 2010. "Speech to the European Parliament." https:// goo.gl/AZJZCL.

Diermeier, Daniel, and Antonio Merlo. 2000. "Government Turnover in Parliamentary Democracies." Iournal of Economic Theory 94 (1): 46-79.

ECB (European Central Bank). 2011. "The European Stability Mechanism." European Central Bank Monthly Bulletin, July, 71-84.

Enelow, James M., and Melvin J. Hinich. 1982. "Nonspatial Candidate Characteristics and Electoral Competition." Iournal of Politics 44 (1): 115-30.

Epstein, Lee, Daniel E. Ho, Gary King, and Jeffrey A. Segal. 2005. "The Supreme Court during Crisis: How War Affects Only Non-war Cases." New York University Law Review 80:1-116.

European Commission. 2013. "A Comprehensive EU Response to the Financial Crisis: Substantial Progress towards a Strong Financial Framework for Europe and a Banking Union for the Eurozone." Memo no. 14/244.

European Commission. 2015. "Proposal for a Regulation of the European Parliament and of the Council on the European Border and Coast Guard." Procedure no. 2015/0310/COD, presented to the European Parliament.

European Union. 2007. "Treaty of Lisbon Amending the Treaty on European Union and the Treaty Establishing the European Community." 2007/C 306/01, December 13.

Groseclose, Tim. 2001. "A Model of Candidate Location When One Candidate Has a Valence Advantage." American Journal of Political Science 45 (4): 862-86.

Hix, Simon. 2002. "Parliamentary Behaviour with Two Principals: Preferences, Parties, and Voting in the European Parliament." American Journal of Political Science 46 (3): 688-98.

Hix, Simon. 2009. "What to Expect in the 2009-14 European Parliament: Return of the Grand Coalition?" Swedish Institute for European Policy Studies-European Policy Analysis 8:1-12.

Hix, Simon, and Bjørn Høyland. 2011. The Political System of the European Union. Basingstoke: Palgrave Macmillan.

Hix, Simon, and Abdul Noury. 2009. "After Enlargement: Voting Patterns in the Sixth European Parliament.” Legislative Studies Quarterly 34 (2): 159-74. 
Hix, Simon, Abdul Noury, and Gérard Roland. 2006. "Dimensions of Politics in the European Parliament." American Journal of Political Science 50 (2): 494-511.

Hix, Simon, Abdul Noury, and Gérard Roland. 2007. Democratic Politics in the European Parliament. Cambridge: Cambridge University Press.

Holinski, Nils, Clemens J. M. Kool, and Joan Muysken. 2012. "Persistent Macroeconomic Imbalances in the Euro Area: Causes and Consequences." Federal Reserve Bank of St. Louis Review 94 (1): 1-20.

Hooghe, Liesbet. 2005. "Several Roads Lead to International Norms, but Few Via International Socialization: A Case Study of the European Commission." International Organization 59 (4): 861-98.

Howell, William G., and Jon C. Rogowski. 2013. "War, the Presidency, and Legislative Voting Behavior." American Journal of Political Science 57 (1): 150-66

Høyland, Bjørn. 2010. "Procedural and Party Effects in European Parliament Roll-Call Votes." European Union Politics 11 (4): 597-613.

Jeong, Gyung-Ho, Gary J. Miller, and Itai Sened. 2009. "Closing the Deal: Negotiating Civil Rights Legislation.” American Political Science Review 103 (4): 588-606.

Kármán, András. 2011. "Speech to the European Parliament." http:// goo.gl/etE7b8.

Keeler, John T. S. 1993. "Opening the Window for Reform Mandates, Crises, and Extraordinary Policy-Making." Comparative Political Studies 25 (4) 433-86.

Kingdon, John W. 1995. Agendas, Alternatives, and Public Policies. 2nd ed. New York: Harper Collins.

Klüver, Heike, and Jae-Jae Spoon. 2015. "Bringing Salience Back In: Explaining Voting Defection in the European Parliament." Partv Politics 21 (4): 553-64.

Krasner, Stephen D. 1984. "Approaches to the State: Alternative Conceptions and Historical Dynamics." Comparative Politics 16 (2): 223-46.

Kreppel, Amie. 2000. "Rules, Ideology and Coalition Formation in the European Parliament: Past, Present and Future." European Union Politics 1 (3): 340-62.

Kreppel, Amie. 2002. The European Parliament and Supranational Party System: A Study in Institutional Development. Cambridge: Cambridge University Press

Kreppel, Amie, and Simon Hix. 2003. 'From 'Grand Coalition' to LeftRight Confrontation: Explaining the Shifting Structure of Party Competition in the European Parliament." Comparative Political Studies 36 (1/2): 75-96.

Kreppel, Amie, and George Tsebelis. 1999. "Coalition Formation in the European Parliament.” Comparative Political Studies 32 (8): 933-66.

Ladd, Jonathon McDonald. 2007. "Predispositions and Public Support for the President during the War on Terrorism." Public Opinion Quarterly 71 (4): 511-38.

Lane, Philip R. 2012. "The European Sovereign Debt Crisis." Lournal of Economic Perspectives 26 (3): 49-68.

Lannoo, Karel. 2011. "The EU's Response to the Financial Crisis: A MidTerm Review." Policy brief no. 241, presented at the Center for European Policy Studies, Brussels.

Luong, Pauline Jones, and Erika Weinthal. 2004. "Contra Coercion: Russian Tax Reform, Exogenous Shocks, and Negotiated Institutional Change.” American Political Science Review 98 (1): 139-52.

Lupia, Arthur, and Kaare Strøm. 1995. "Coalition Termination and the Strategic Timing of Parliamentary Elections." American Political Science Review 89 (3): 648-65.

Martinez-Gallardo, Cecilia. 2011. "Designing Cabinets: Presidential Politics and Cabinet Instability in Latin America." Working paper no. 375, University of Notre Dame, Kellogg Institute.
Mattila, Mikko. 2004. "Contested Decisions: Empirical Analysis of Voting in the European Council of Ministers." European Journal of Political Research 43:29-50.

McElroy, Gail, and Kenneth Benoit. 2007. "Party Groups and Policy Positions in the European Parliament." Party Politics 13 (1): 5-28.

McElroy, Gail, and Kenneth Benoit. 2011. "Policy Positioning in the European Parliament." European Union Politics 13 (1): 150-67.

Meernik, James. 1993. "Presidential Support in Congress: Conflict and Consensus on Foreign and Defense Policy." Journal of Politics 55 (3): 569-87.

Muehlboeck, Monika, and Nikoleta Yordanova. 2012. "Party Group Cohesion in the European Parliament: Tracing the Bias in Roll-Call Votes." Presented at the 2nd Annual General Conference of the European Political Science Association, Berlin.

Paulo, Sebastian. 2011. "Europe and the Global Financial Crisis: Taking Stock of the EU's Policy Response." https://www.robert-schuman.eu /en/dossiers-pedagogiques/crise-financiere/crise-economique-mondiale -en-10-fiches-qe-200-en.pdf.

Peters, B. Guy, Jon Pierre, and Desmond S. King. 2005. "The Politics of Path Dependency: Political Conflict in Historical Institutionalism." Lournal of Politics 67 (4): 1275-300.

Pierson, Paul. 2000. "Increasing Returns, Path Dependence, and the Study of Politics." American Political Science Review 94 (2): 251-67.

Poole, Keith T., and Howard L. Rosenthal. 2011. Ideology and Congress, vol. 1. Abingdon: Transaction.

Prins, Brandon C., and Bryan W. Marshall. 2001. "Congressional Support of the President: A Comparison of Foreign, Defense, and Domestic Policy Decision Making during and after the Cold War." Presidential Studies Quarterly 31 (4): 660-78.

Roberts, Margaret E., Brandon M. Stewart, Dustin Tingley, Christopher Lucas, Jetson Leder-Luis, Shana Kushner Gadarian, Bethany Albertson, and David G. Rand. 2014. "Structural Topic Models for Open-Ended Survey Responses.” American Journal of Political Science 58 (4): 1064-82.

Romer, Thomas, and Howard Rosenthal. 1978. "Political Resource Allocation, Controlled Agendas, and the Status Quo." Public Choice 33 (4): $27-43$.

Schimmelfennig, Frank. 2014. "European Integration in the Euro Crisis: The Limits of Postfunctionalism." Lournal of European Integration 36 (3): $321-37$.

Schmidt, Susanne K. 2001. "A Constrained Commission: Informal Practices of Agenda-Setting in the Council." In Gerald Schneider and Mark Aspinwall, eds., The Rules of Integration: Institutionalist Approaches to the Study of Europe. Manchester: Manchester University Press, 125-46.

Stan Development Team. 2014. "Stan: A C + + Library for Probability and Sampling, Version 2.2." http://mc-stan.org/.

Thelen, Kathleen. 2004. How Institutions Evolve: The Political Economy of Skills in Germany, Britain, the United States, and Japan. Cambridge: Cambridge University Press.

Tsebelis, George. 2002. Veto Plavers: How Political Institutions Work. Princeton, NJ: Princeton University Press.

Tsebelis, George, and Hyeonho Hahm. 2014. "Suspending Vetoes: How the Euro Countries Achieved Unanimity in the Fiscal Compact." Journal of European Public Policy 21 (10): 1388-411.

Tsebelis, George, and Amie Kreppel. 1998. "The History of Conditional Agenda-Setting in European Institutions." European Journal of Political Research 33 (1): 41-71.

Warntjen, Andreas, Simon Hix, and Christophe Crombez. 2008. "The Party Political Make-Up of EU Legislative Bodies." Lournal of European Public Policy 15 (8): 1243-53.

Williams, Russell Alan. 2009. "Exogenous Shocks in Subsystem Adjustment and Policy Change: The Credit Crunch and Canadian Banking Regulation." Lournal of Public Policy 29 (1): 29-53. 